\title{
Assessing Reliable Software using SPRT based on LPETM
}

\author{
R. Satya Prasad \\ $\mathrm{PhD}$, Associate Professor \\ Dept. of CS \&Engg. \\ AcharyaNagarjuna University
}

\author{
D. Haritha \\ Assistant Professor \\ Dept. of Electronics \& \\ Computer Engg. \\ K.L.University
}

R. Sindhura
Dept. of CSE
K.L.University

\begin{abstract}
Software reliability assessment is increasingly important in developing and testing new software products. Logarithmic Poisson Execution Time Model (LPETM) is a software reliability model which predicts the expected failures and hence related reliability quantities better than existing software reliability models. It uses Non-Homogeneous Poisson Process(NHPP) with a mean value function that is dependent on exponentially falling fault detection rate. The well known sequential Probability Ratio Test(SPRT) procedure of statistical science is adopted for this model in order to decide upon the reliability / unreliability of developed software. The model is evaluated by using 6 Data Sets.
\end{abstract}

\section{General Terms}

Decision Rule, Software testing, Software failure data,Quality Software.

\section{Keywords}

LPETM, Maximum Likelihood Estimation, Unreliable Software, Mean value function, Intensity function.

\section{INTRODUCTION}

In the analysis of software failure data we often deal with either inter failure times or number of recorded failures in a given time interval. If it is further assumed that the average number of recorded failures in a given time interval is directly proportional to the length of the interval and the random number of failure occurrences in the interval is explained by a Poisson process then we know that the probability equation of the stochastic process representing the failure occurrences is given by a homogeneous Poisson process with the expression

$P[N(t)=n]=\frac{e^{-\lambda t}(\lambda t)^{n}}{n !}$

Stieber (1997) observes that if classical testing strategies are used (no usage testing), the application of software reliability growth models may be difficult and reliability predictions can be misleading. However, he observes that statistical methods can be successfully applied to the failure data. He demonstrated his observation by applying the wellknown sequential probability ratio test (SPRT) of Wald (1947) for a software failure data to detect unreliable software components and compare the reliability of different software versions. In this paper we consider a popular SRGM proposed by Goel and Okumoto(1979) and adopt the principle of Stieber (1997) in detecting unreliable software components in order to accept/reject a developed software. For brevity we denote the SRGM as GOM. The failure intensity is linearly decreasing in its mean value function. The theory proposed by Stieber (1997) is presented in Section 2 for a ready reference. Extension of this theory to the LPETM is presented in Section 3. The procedure for parameter estimation is presented in section 4. Application of the decision rule to detect unreliable software components with respect to the proposed SRGM is given in Section 5.

\section{WALD'S SEQUENTIAL TEST FOR A POISSON PROCESS}

The sequential probability ratio test (SPRT) was developed by A.Wald at Columbia University in 1943. Due to its usefulness in development work on military and naval equipment it was classified as 'Restricted' by the Espionage Act ( Wald, 1947). A big advantage of sequential tests is that they require fewer observations (time) on the average than fixed sample size tests. SPRTs are widely used for statistical quality control in manufacturing processes. An SPRT for homogeneous Poisson processes is described below.

Let $\{\mathrm{N}(\mathrm{t}), \mathrm{t} \geq 0\}$ be a homogeneous Poisson process with rate ' $\lambda$ '. In our case, $\mathrm{N}(\mathrm{t})=$ number of failures up to time ' $\mathrm{t}$ ' and ' $\lambda$ ' is the failure rate (failures per unit time ). Suppose that we put a system on test (for example a software system, where testing is done according to a usage profile and no faults are corrected) and that we want to estimate its failure rate ' $\lambda$ '. We cannot expect to estimate ' $\lambda$ ' precisely. But we want to reject the system with a high probability if our data suggest that the failure rate is larger than $\lambda_{1}$ and accept it with a high probability, if it's smaller than $\lambda_{0}\left(0<\lambda_{0}<\lambda_{1}\right)$. As always with statistical tests, there is some risk to get the wrong answers. So we have to specify two (small) numbers ' $\alpha$ ' and ' $\beta$ ', where ' $\alpha$ ' is the probability of falsely rejecting the system. That is rejecting the system even if $\lambda \leq \lambda_{0}$. This is the "producer's" risk. $\beta$ is the probability of falsely accepting the system .That is accepting the system even if $\lambda \geq \lambda_{1}$. This is the "consumer's" risk. With specified choices of $\lambda_{0}$ and $\lambda_{1}$ such that $0<\lambda_{0}<\lambda_{1}$, the probability of finding $\mathrm{N}(\mathrm{t})$ failures in the time span $(0, \mathrm{t})$ with $\lambda_{1}, \lambda_{0}$ as the failure rates are respectively given by

$$
\begin{aligned}
& P_{1}=\frac{e^{-\lambda_{1} t}\left[\lambda_{1} t\right]^{N(t)}}{N(t) !} \\
& P_{0}=\frac{e^{-\lambda_{0} t}\left[\lambda_{0} t\right]^{N(t)}}{N(t) !}
\end{aligned}
$$

The ratio $\frac{P_{1}}{P_{0}}$ at any time't' is considered as a measure of deciding the truth towards $\lambda_{0}$ or $\lambda_{1}$, given a sequence of time instants say $t_{1}<t_{2}<t_{3}<\ldots \ldots . .<t_{K}$ and the 
corresponding realizations. $N\left(t_{1}\right), N\left(t_{2}\right), \ldots \ldots . . N\left(t_{K}\right)$ of N(t). Simplification of $\frac{P_{1}}{P_{0}}$ gives

$$
\frac{P_{1}}{P_{0}}=\exp \left(\lambda_{0}-\lambda_{1}\right) t+\left(\frac{\lambda_{1}}{\lambda_{0}}\right)^{N(t)}
$$

The decision rule of SPRT is to decide in favor of $\lambda_{1}$, in favor of $\lambda_{0}$ or to continue by observing the number of failures at a later time than 't' according as $\frac{P_{1}}{P_{0}}$ is greater than or equal to a constant say $\mathrm{A}$, less than or equal to a constant say B or in between the constants A and B. That is, we decide the given software product as unreliable, reliable or continue the test process with one more observation in failure data, according as

$$
\begin{aligned}
& \frac{P_{1}}{P_{0}} \geq A \\
& \frac{P_{1}}{P_{0}} \leq B \\
& B<\frac{P_{1}}{P_{0}}<A
\end{aligned}
$$

The approximate values of the constants A and B are taken as

$A \cong \frac{1-\beta}{\alpha}, \quad \mathrm{B} \cong \frac{\beta}{1-\alpha}$

Where ' $\alpha$ ' and ' $\beta$ ' are the risk probabilities as defined earlier. A simplified version of the above decision processes is to reject the system as unreliable if $\mathrm{N}(\mathrm{t})$ falls for the first time above the line

$$
N_{U}(t)=a . t+b_{2}
$$

to accept the system to be reliable if $\mathrm{N}(\mathrm{t})$ falls for the first time below the line

$$
N_{L}(t)=a . t-b_{1}
$$

To continue the test with one more observation on $(t, N(t))$ as the random graph of $[\mathrm{t}, \mathrm{N}(\mathrm{t})]$ is between the two linear boundaries given by equations (2.6) and (2.7) where

$$
a=\frac{\lambda_{1}-\lambda_{0}}{\log \left(\frac{\lambda_{1}}{\lambda_{0}}\right)}
$$

$$
b_{1}=\frac{\log \left[\frac{1-\alpha}{\beta}\right]}{\log \left(\frac{\lambda_{1}}{\lambda_{0}}\right)}
$$

$$
b_{2}=\frac{\log \left[\frac{1-\beta}{\alpha}\right]}{\log \left(\frac{\lambda_{1}}{\lambda_{0}}\right)}
$$

The parameters $\alpha, \beta, \lambda_{0}$ and $\lambda_{1}$ can be chosen in several ways. One way suggested by Stieber (1997) is

$$
\begin{aligned}
& \lambda_{0}=\frac{\lambda \cdot \log (q)}{q-1}, \lambda_{1}=q \frac{\lambda \cdot \log (q)}{q-1} \\
& \text { where } q=\frac{\lambda_{1}}{\lambda_{0}}
\end{aligned}
$$

If $\lambda_{0}$ and $\lambda_{1}$ are chosen in this way, the slope of $\mathrm{N}_{\mathrm{U}}(\mathrm{t})$ and $\mathrm{N}_{\mathrm{L}}(\mathrm{t})$ equals $\lambda$. The other two ways of choosing $\lambda_{0}$ and $\lambda_{1}$ are from past projects (for a comparison of the projects) and from part of the data to compare the reliability of different functional areas (components).

\section{SEQUENTIAL TEST FOR SOFTWARE RELIABILITY GROWTH MODEL}

In Section 2, for the Poisson process we know that the expected value of $\mathrm{N}(\mathrm{t})=\lambda \mathrm{t}$ called the average number of failures experienced in time ' $\mathrm{t}$ '. This is also called the mean value function of the Poisson process. On the other hand if we consider a Poisson process with a general function (not necessarily linear) $m(t)$ as its mean value function the probability equation of a such a process is

$$
P[N(t)=Y]=\frac{[m(t)]^{y}}{y !} \cdot e^{-m(t)}, y=0,1,2,----
$$

Depending on the forms of $\mathrm{m}(\mathrm{t})$ we get various Poisson processes called NHPP for our model the mean value function is

$m(t)=a \cdot \log (1+b t)$

We may write

$$
\begin{aligned}
& P_{1}=\frac{e^{-m_{1}(t)} \cdot\left[m_{1}(t)\right]^{N(t)}}{N(t) !} \\
& P_{0}=\frac{e^{-m_{0}(t)} \cdot\left[m_{0}(t)\right]^{N(t)}}{N(t) !}
\end{aligned}
$$


where $m_{1}(t), m_{0}(t)$ are values of the mean value function at specified sets of its parameters indicating reliable software and unreliable software respectively. For instance the model we have been considering its $\mathrm{m}(\mathrm{t})$ function, contains a pair of parameters a, b with ' $a$ ' as a multiplier. Also a, b are positive. Let $P_{0}, P_{1}$ be values of the NHPP at two specifications of $\mathrm{b}$ say $b_{0}, b_{1}\left(b_{0}<b_{1}\right)$ respectively. It can be shown that for our models $m(t)$ at $b_{1}$ is greater than that at $b_{0}$. Symbolically $\mathrm{m}_{0}(\mathrm{t})<\mathrm{m}_{1}(\mathrm{t})$.Then the SPRT procedure is as follows:

Accept the system to be reliable $\frac{P_{1}}{P_{0}} \leq B$

i.e., $\frac{e^{-m_{1}(t)} \cdot\left[m_{1}(t)\right]^{N(t)}}{e^{-m_{0}(t)} \cdot\left[m_{0}(t)\right]^{N(t)}} \leq B$

i.e., $N(t) \leq \frac{\log \left(\frac{\beta}{1-\alpha}\right)+m_{1}(t)-m_{0}(t)}{\log m_{1}(t)-\log m_{0}(t)}$

Decide the system to be unreliable and reject if $\frac{P_{1}}{P_{0}} \geq A$

i.e., $N(t) \geq \frac{\log \left(\frac{1-\beta}{\alpha}\right)+m_{1}(t)-m_{0}(t)}{\log m_{1}(t)-\log m_{0}(t)}$

Continue the test procedure as long as

$$
\frac{\log \left(\frac{\beta}{1-\alpha}\right)+m_{1}(t)-m_{0}(t)}{\log m_{1}(t)-\log m_{0}(t)}<N(t)<\frac{\log \left(\frac{1-\beta}{\alpha}\right)+m_{1}(t)-m_{0}(}{\log m_{1}(t)-\log m_{0}(t)}
$$

Substituting the appropriate expressions of the mean value function $-m(t)$ of LPETM we get the decision rules and are given in followings lines

$m(t)=a \cdot \log (1+b t)$

Acceptance region:

$$
N(t) \leq \frac{\log \left(\frac{\beta}{1-\alpha}\right)+a\left(e^{-b_{0} t}-e^{-b_{1} t}\right)}{\log \left(\frac{1-e^{-b_{1} t}}{1-e^{-b_{0} t}}\right)}
$$

Rejection region:

$$
N(t) \geq \frac{\log \left(\frac{1-\beta}{\alpha}\right)+a\left(e^{-b_{0} t}-e^{-b_{1} t}\right)}{\log \left(\frac{1-e^{-b_{1} t}}{1-e^{-b_{0} t}}\right)}
$$

Continuation region:

$$
\frac{\log \left(\frac{\beta}{1-\alpha}\right)+a\left(e^{-b_{0} t}-e^{-b_{t} t}\right)}{\log \left(\frac{1-e^{-b_{t} t}}{1-e^{-b_{0} t}}\right)}<N(t)<\frac{\log \left(\frac{1-\beta}{\alpha}\right)+a\left(e^{-b_{0} t}-e^{-b_{t} t}\right)}{\log \left(\frac{1-e^{-b_{t} t}}{1-e^{-b_{0} t}}\right)}
$$

It may be noted that in the above model the decision rules are exclusively based on the strength of the sequential procedure $(\alpha, \beta)$ and the values of the mean value functions namely, $m_{0}(t), m_{1}(t)$. If the mean value function is linear in ' $\mathrm{t}$ ' passing through origin, that is, $\mathrm{m}(\mathrm{t})=\lambda \mathrm{t}$ the decision rules become decision lines as described by Stieber (1997). In that sense equations (3.1), (3.2) , (3.3) can be regarded as generalizations to the decision procedure of Stieber (1997).The applications of these results for live software failure data are presented with analysis in Section 4.

\section{PARAMETER ESTIMATION}

Parameter estimation is of primary importance in software reliability prediction. Once the analytical solution for $m(t)$ is known for a given model, parameter estimation is achieved by applying a well known technique of Maximum Likelihood Estimation (MLE). Depending on the format in which test data are available, two different approaches are frequently used. A set of failure data is usually collected in one of two common ways, time domain data and interval domain data. The idea behind maximum likelihood parameter estimation is to determine the parameters that maximize the probability (likelihood) of the sample data. The method of maximum likelihood is considered to be more robust (with some exceptions) and yields estimators with good statistical properties. In other words, MLE methods are versatile and apply to most models and to different types of data. Although the methodology for maximum likelihood estimation is simple, the implementation is mathematically intense.

Assuming that the data are given for the cumulative number of detected errors yi in a given time-interval $\left(0, \mathrm{t}_{\mathrm{i}}\right)$ where $\mathrm{i}=1,2, \ldots, \mathrm{n}$. and $0<\mathrm{t}_{1}<\mathrm{t}_{2}<\ldots<\mathrm{t}_{\mathrm{n}}$ then the $\log$ likelihood function (LLF) takes on the following form. Likely hood function by using $\lambda(\mathrm{t})$ is: $L=\prod_{i=1}^{n} \lambda\left(t_{i}\right)$.The logarithmic likelihood function for interval domain data (pham, 2006) is given by:

$\log L=\sum_{i=1}^{n}\left(y_{i}-y_{i-1}\right) \log \left[\mathrm{m}\left(\mathrm{t}_{\mathrm{i}}\right)-\mathrm{m}\left(\mathrm{t}_{\mathrm{i}-1}\right)\right]-\mathrm{m}\left(\mathrm{t}_{\mathrm{n}}\right)$

The maximum likelihood estimators (MLE) of $\Theta_{1}, \Theta_{2}, \ldots, \Theta_{k}$ are obtained by maximizing $\mathrm{L}$ or $\Lambda$, where $\Lambda_{\text {is }} \ln \mathrm{L}$. By maximizing $\Lambda$, which is much easier to work with than $\mathrm{L}$, the maximum likelihood estimators (MLE) of $\theta_{1}, \theta_{2}, \ldots, \theta_{k}$ are the simultaneous solutions of $\mathrm{k}$ equations such that: 


$$
\frac{\partial(\Lambda \Lambda)}{\partial \theta_{j}}=0 \mathrm{j}=1,2, \ldots, \mathrm{k}
$$

The parameters ' $a$ ' and ' $b$ ' are estimated using iterative Newton Raphson Method, which is given as $x_{n+1}=x_{n}-\frac{f\left(x_{n}\right)}{f^{\prime}\left(x_{n}\right)}$

To estimate ' $\mathrm{a}$ ' and ' $\mathrm{b}$ ', for a sample of $\mathrm{n}$ units, first obtain the likelihood function: $L=\prod_{i=1}^{n} a b e^{-b t}$ Take the natural logarithm on both sides, The Log Likelihood function is given as: $\quad \log L=\log \left[\prod_{i=1}^{n} \lambda\left(t_{i}\right)\right]$

$$
\begin{aligned}
= & \log \left[\prod_{i=1}^{n} a b e^{-b t}\right] \\
= & \sum_{i=1}^{n}\left(y_{i}-y_{i-1}\right) \log \left[\left(a \cdot \log \left[1+b t_{i}\right]\right)-\left(a \cdot \log \left[1+b t_{i-1}\right]\right)\right]- \\
& \quad a \cdot \log \left[1+b t_{n}\right]
\end{aligned}
$$

The parameter ' $a$ ' is estimated by taking the partial derivative w.r.t 'a' and equating it to ' 0 '. (i.e $\frac{\partial \log L}{\partial a}=0$ )

$$
a=\frac{\sum_{i=1}^{n}\left(y_{i}-y_{i-1}\right)}{\log \left[\left[_{1}+b t_{n}\right]\right.}
$$

The parameter ' $b$ ' is estimated by iterative Newton Raphson Method using $b_{n+1}=b_{n}-\frac{g\left(b_{n}\right)}{g^{\mid}\left(b_{n}\right)}$. which is substituted in finding ' $a$ '. where $\mathrm{g}(\mathrm{b}) \& \mathrm{~g}(\mathrm{~b})$ are expressed as follows.

$$
\begin{gathered}
g(b)=\frac{\partial \log L}{\partial b}=0 \quad ; \quad g^{\prime}(b)=\frac{\partial^{2} \log L}{\partial b^{2}}=0 \\
\mathrm{~g}(\mathrm{~b})=\sum_{i=1}^{n}\left[y_{i}-y_{i-1}\right]\left[t_{i}-t_{i-1}\right]\left[\frac{\log \left[1+b t_{i-1}\right]-\log \left[1+b t_{i}\right]}{\left[1+b t_{i}\right]\left[1+b t_{i-1}\right]}\right]-\frac{a t_{n}}{1+b t_{n}}
\end{gathered}
$$$$
g^{\prime}(b)=
$$$$
\sum_{i=1}^{n}\left[y_{i}-y_{i-1}\right]\left[t_{i}-\right.
$$$$
\left.t_{i-1}\right] \frac{\left[\left(t_{i-1}-t_{i}\right)+\left(t_{i}+t_{i-1}+2 b t_{i} t_{i-1}\right)\left[\log \frac{\left(1+b t_{i}\right)}{\left(1+b t_{i-1}\right)}\right]\right.}{\left(1+b t_{i}\right)^{2}\left(1+b t_{i-1}\right)^{2}}
$$

$$
+\frac{\sum_{i=1}^{n}\left[y_{i}-y_{i-1}\right]}{\log \left[\frac{[1}{1}+b t_{n}\right]} X \frac{t_{n}^{2}}{\left(1+b t_{n}\right)^{2}}
$$

\section{SPRT ANALYSIS OF LIVE DATA}

\section{SETS}

We see that the developed SPRT methodology is for a software failure data which is of the form $[t, N(t)]$ where $N(t)$ is the observed number of failures of software system or its sub system in ' $t$ ' units of time. In this section we evaluate the decision rules based on the considered mean value functions for six different data sets of the above form, borrowed from Wood (1996), Pham (2005). Based on the estimates of the parameter ' $b$ ' in each mean value function, we have chosen the specifications of $b_{0}, b_{1}$ equidistant on either side of estimate of $\sum \quad b$ obtained through a Data Set to apply SPRT such that $b_{0}<b<b_{1}$. The choices are given in the following table.

Table 5.1: Specifications of b0, b1

\begin{tabular}{|c|c|c|c|c|}
\hline Data Set & $\mathbf{T}$ & $\mathbf{N}(\mathbf{t})$ & $\begin{array}{c}\text { R.H.S of equation } \\
(\mathbf{3 . 4 )} \\
\text { Acceptance region ( }(\leq)\end{array}$ & $\begin{array}{c}\text { R.H.S of Equation } \\
\text { (3.5) } \\
\text { Rejection Region( } \geq) \\
\end{array}$ \\
\hline $\begin{array}{l}\text { Pham(2005) } \\
\text { Phase } 1 \text { Data }\end{array}$ & $\begin{array}{l}356 \\
712 \\
1068 \\
1424 \\
1780 \\
2136 \\
2492 \\
\end{array}$ & $\begin{array}{l}1 \\
1 \\
2 \\
3 \\
5 \\
5 \\
5\end{array}$ & $\begin{array}{r}-1.4008 \\
-0.1456 \\
1.0866 \\
2.2965 \\
3.4853 \\
4.6536 \\
5.8023 \\
\end{array}$ & $\begin{array}{c}4.0026 \\
5.3004 \\
6.5746 \\
7.8261 \\
9.0558 \\
10.2646 \\
11.4533 \\
\end{array}$ \\
\hline $\begin{array}{l}\text { Pham (2005) } \\
\text { Phase } 2 \text { Data }\end{array}$ & $\begin{array}{l}416 \\
832 \\
1248 \\
1664 \\
2080 \\
2496\end{array}$ & $\begin{array}{l}3 \\
4 \\
4 \\
7 \\
9 \\
9\end{array}$ & $\begin{array}{l}1.1826 \\
3.3781 \\
5.5202 \\
7.6118 \\
9.6552\end{array}$ & $\begin{array}{c}5.7729 \\
8.1035 \\
10.3763 \\
12.5945 \\
14.7607 \\
16.8777\end{array}$ \\
\hline
\end{tabular}

\begin{tabular}{|c|l|l|l|l|}
\hline Data Set & $\begin{array}{c}\text { Estima } \\
\text { te of a }\end{array}$ & $\begin{array}{l}\text { Estimate } \\
\text { of b }\end{array}$ & $\mathbf{b}_{\mathbf{0}}$ & $\mathbf{b}_{\mathbf{1}}$ \\
\hline $\begin{array}{c}\text { Pham (2005) } \\
\text { Phase 1 Data }\end{array}$ & 81.06 & 0.000050 & 0.000025 & 0.000075 \\
\hline $\begin{array}{c}\text { Pham (2005) } \\
\text { Phase 2 Data }\end{array}$ & 99.77 & 0.000061 & 0.000036 & 0.000086 \\
\hline $\begin{array}{c}\text { Wood (1996) } \\
\text { Release 1 } \\
\text { Data }\end{array}$ & 59.93 & 0.000444 & 0.000419 & 0.000469 \\
\hline $\begin{array}{c}\text { Wood (1996) } \\
\text { Release 2 } \\
\text { Data }\end{array}$ & 126.71 & 0.000155 & 0.000130 & 0.000180 \\
\hline $\begin{array}{c}\text { Wood (1996) } \\
\text { Release 3 } \\
\text { Data }\end{array}$ & 48.38 & 0.000501 & 0.000476 & 0.000526 \\
\hline $\begin{array}{c}\text { Wood (1996) } \\
\text { Release 4 } \\
\text { Data }\end{array}$ & 40.94 & 0.000159 & 0.000134 & 0.000184 \\
\hline
\end{tabular}

Using the selected $b_{0}, b_{1}$ and subsequently the $m_{0}(t), m_{1}(t)$ for each model we calculated the decision rules given by Equations 3.4, 3.5, sequentially at each ' $t$ ' of the data sets taking the strength $(\alpha, \beta)$ as $(0.05,0.05)$. These are presented for the model in Tables 5.2.

Table 5.2: SPRT for LPETM 


\begin{tabular}{|c|c|c|c|c|}
\hline $\begin{array}{l}\text { Wood (1996) } \\
\text { Release 1 Data }\end{array}$ & $\begin{array}{l}529 \\
968 \\
1430 \\
1893 \\
2490 \\
3058 \\
3625 \\
4422 \\
5218 \\
5823 \\
6539 \\
7083 \\
7487 \\
7846 \\
8205 \\
8564 \\
8923 \\
9282 \\
9641 \\
10000 \\
\end{array}$ & \begin{tabular}{|l|}
16 \\
24 \\
27 \\
33 \\
41 \\
49 \\
54 \\
58 \\
69 \\
75 \\
81 \\
86 \\
90 \\
93 \\
96 \\
98 \\
99 \\
100 \\
100 \\
100 \\
\end{tabular} & $\begin{array}{c}-16.6825 \\
-9.9658 \\
-4.0506 \\
1.1120 \\
6.9060 \\
11.7203 \\
15.9940 \\
212939 \\
25.9377 \\
29.1195 \\
32.5651 \\
34.9845 \\
36.6840 \\
38.1311 \\
39.5233 \\
40.8646 \\
42.1583 \\
43.4078 \\
44.6187 \\
45.7848 \\
\end{array}$ & $\begin{array}{c}41.1524 \\
52.1541 \\
62.0586 \\
70.8726 \\
80.9573 \\
89.4948 \\
97.1955 \\
106.9067 \\
115.5639 \\
121.5758 \\
128.1601 \\
132.8296 \\
136.1323 \\
138.9593 \\
141.6918 \\
144.3362 \\
146.8979 \\
148.3822 \\
151.7935 \\
154.1361 \\
\end{array}$ \\
\hline $\begin{array}{c}\text { Wood (1996) } \\
\text { Release 2 Data }\end{array}$ & 384 & 13 & -2.0491 & 16.5704 \\
\hline $\begin{array}{l}\text { Wood (1996) } \\
\text { Release } 3 \text { Data }\end{array}$ & $\begin{array}{c}162 \\
499 \\
715 \\
1137 \\
1799 \\
2438 \\
2818 \\
3574 \\
4234 \\
4680 \\
4955 \\
5053 \\
\end{array}$ & $\begin{array}{c}6 \\
9 \\
12 \\
20 \\
28 \\
40 \\
48 \\
54 \\
57 \\
59 \\
60 \\
61 \\
\end{array}$ & $\begin{array}{c}-26.8706 \\
-22.1002 \\
-19.4170 \\
-14.8214 \\
-8.8866 \\
-4.1957 \\
-1.7621 \\
2.4799 \\
5.6728 \\
7.6172 \\
8.7430 \\
9.1318 \\
\end{array}$ & $\begin{array}{c}34.4153 \\
43.6736 \\
49.0173 \\
58.4085 \\
71.0073 \\
81.3632 \\
86.8806 \\
96.7442 \\
104.3809 \\
109.1235 \\
111.9018 \\
112.8670 \\
\end{array}$ \\
\hline $\begin{array}{l}\text { Wood (1996) } \\
\text { Release } 4 \text { Data }\end{array}$ & $\begin{array}{c}254 \\
788 \\
1054\end{array}$ & $\begin{array}{l}1 \\
3 \\
8\end{array}$ & $\begin{array}{c}7.8618 \\
-5.0486 \\
-3.7291\end{array}$ & $\begin{array}{l}11.0764 \\
14.6306 \\
16.3050\end{array}$ \\
\hline
\end{tabular}

From the above table we see that a decision either to accept or reject the system is reached much in advance of the last time instant of the data(the testing time). The following consolidated table reveals the iterations required to come to a decision about the software of each Data Set.

Table 5.3: Consolidated Table of Decisions

\begin{tabular}{|l|c|c|c|}
\hline Data Set & $\begin{array}{c}\text { LPETM } \\
\text { Model }\end{array}$ & Iterations & Decision \\
\hline $\begin{array}{c}\text { Pham (2005) } \\
\text { Phase 1 Data }\end{array}$ & 0.9752 & 7 & Accept \\
\hline $\begin{array}{c}\text { Pham (2005) } \\
\text { Phase 2 Data }\end{array}$ & 0.9961 & 6 & Accept \\
\hline $\begin{array}{c}\text { Wood (1996) } \\
\text { Release 1 } \\
\text { Data }\end{array}$ & 0.9742 & 21 & Continuous \\
\hline $\begin{array}{c}\text { Wood (1996) } \\
\text { Release 2 } \\
\text { Data }\end{array}$ & 0.9742 & 20 & Continuous \\
\hline $\begin{array}{c}\text { Wood (1996) } \\
\text { Release 3 } \\
\text { Data }\end{array}$ & 0.9290 & 13 & Continuous \\
\hline $\begin{array}{c}\text { Wood (1996) } \\
\text { Release 4 } \\
\text { Data }\end{array}$ & 0.9672 & 20 & Continuous \\
\hline
\end{tabular}

The above consolidated table shows that LPETM as exemplified for 6 Data Sets indicate that the model is performing well for 2 Data Sets in arriving at a decision. For the remaining 4 Data Sets LPTEM is inconclusive. Therefore, we may conclude that the model LPETM is most appropriate model to decide upon reliability / unreliability of software. The authors are exploring the possibility of performance of a new SRGM generated on the basis of dependence of mean value function on the fault detection rate in a exponentially decreasing manner.

\section{REFERENCES}

[1] GOEL, A.L and OKUMOTO, K. (1979). "A Time Dependent Error Detection Rate Model For Software Reliability And Other Performance Measures", IEEE Transactions on Reliability, vol.R-28, pp.206-211, 1979.

[2] MUSA, J.D., and OKUMOTO, K. (1984). "A Logorithmic Poisson Execution Time Model For Software Reliability Measurement", Proceeding Seventh International Conference on Software Engineering, Orlando, 230-238.

[3] PHAM, H.(2005). "A Generalized Logistic Software Reliability Growth Model", OPSEARCH, Vol.42, No.4, 322-331.

[4] Pham. H., 2006. "System software reliability", Springer.

[5] STIEBER, H.A.(1997). "Statistical Quality Control: How To Detect Unreliable Software Components", Proceedings of the 8th International Symposium on Software Reliability Engineering, 8-12. 
[6] WALD (1947).”Sequential Analysis", Wiley,New York.

[7] WOOD, A.(1996)."Predicting Software Reliability”,IEEE Computer, 2253-2264.

[8] R.Satya Prasad and G. Krishna Mohan.(2011)."Detection Of Reliable Software Using SPRT On Time Domain Data",International Journal of Computer Science, Engineering and Applications, Vol.1, No.4, pp.92-99.

[9] R. Satya Prasad, N. Supriya and G. Krishna Mohan (2011)."Detection Of Reliable Software Using SPRT"
International Journal of Advanced Computer Science and Applications Vol.2, No: 8, pp.60-63.

[10] R. Satya Prasad and D. Haritha (2011). “ Discovery of Reliable Software using GOM on Interval Domain Data" , International Journal of Computer Applications Volume 32- No.5, pp.7-12.

[11] R. Satya Prasad and D. Haritha (2011). "Detection of Reliable Software using HLSRGM" , International Journal of Computer Information Systems ,pp.49-53. 